\title{
Simpanan Karbon Di Atas Permukaan Pada Berbagai Penggunaan Lahan Di Hutan Lindung Sirimau, Pulau Ambon
}

\author{
Above-Ground Carbon Stocks under Different Land Uses in Sirimau Protected Forest, Ambon \\ Island
}

\author{
Sandhy H. Luhulima ${ }^{1,2}$, Rafael M. Osok ${ }^{1, *}$, Elizabeth Kaya ${ }^{1}$ \\ ${ }^{1}$ Program Studi Pengelolaan Lahan, Program Pascasarjana Universitas Pattimura, Jln. Dr. Tamaela, Ambon 97112, \\ Indonesia \\ ${ }^{2}$ Dinas Tanaman Pangan Provinsi Maluku, Jalan Pantai Waihong, Ambon 97112, Indonesia \\ "E-mail Penulis Korespondensi: rafmosok2016@gmail.com
}

\begin{abstract}
Forest conversion is a main contributor to land cover changes in the Sirimau protected forest area in Ambon Island, which reduces forest's ability to absorb carbon from the atmosphere. This study aimed to calculate aboveground carbon and potential carbon sequestration in Sirimau protected forest area. Sampling techniques were adapted from the method of Hairiah et al. (2001; 2011) and Wibowo et al. (2013), namely non-destructive (for tress) and destructive methods (for understorey). Data analysis included the calculation of biomass and above-ground carbon stocks (trees and understorey) of all land uses based on Hairiah et al. (2001; 2011). The results showed that total carbon stocks in the Sirimau protected forest was 418.98 ton per ha, consisted of tree carbon stocks, 402.25 ton per ha $(96 \%)$ and understorey 16.69 ton per ha (4\%), whereas the largest carbon stock was found in primary dry land forest of 187.59 ton per ha, secondary dryland forest of 100.48 ton per ha, shrubs of 32.59 ton per ha (7.78\%), agriculture dry land 31.41 ton per ha (7.5\%), mixed dry land and agriculture 59.25 ton per ha (14.14\%), savanna 6.78 ton per ha $(1.62 \%)$ and settlements 0.84 ton per ha $(0.2 \%)$. The potential carbon sequestration in the Sirimau protected forest was 1,537.50 ton $\mathrm{CO}_{2}$ per ha, and the largest absorption was 1,476.25 ton $\mathrm{CO}_{2}$ per ha or $96 \%$ of the total absorbed $\mathrm{CO}_{2}$ by trees. The largest $\mathrm{CO}_{2}$ absorption capacity was 688,45 ton $\mathrm{CO}_{2}$ per ha (44.78\%) by primary dryland forest.
\end{abstract}

Keywords: trees and understorey carbon stocks, carbon sequestration, Sirimau protected-forest, Ambon Island

\begin{abstract}
ABSTRAK
Konversi hutan merupakan penyebab perubahan tutupan lahan di kawasan hutan lindung Sirimau, Pulau Ambon, sehingga mempengaruhi fungsi hutan sebagai penyerap karbon dari atmosfer. Penelitian ini bertujuan untuk mengkaji simpanan dan potensi serapan karbon di atas permukaan pada hutan lindung Sirimau setelah terjadi perubahan penggunaan lahan sejak tahun 2010. Teknik pengambilan sampel diadaptasi dari metode Hairiah et al. (2001; 2011) dan Wibowo et al. (2013), yaitu non-destructive untuk pohon dan destructive untuk tumbuhan bawah. Analisis data meliputi perhitungan biomasa dan cadangan karbon di atas permukaan (pohon dan tumbuhan bawah) pada semua penggunaan lahan dengan mengacu pada Hairiah et al. (2001; 2011). Hasil penelitian menunjukkan bahwa total simpanan karbon pada hutan lindung Gunung Sirimau adalah 418,98 ton per ha, yang berasal dari cadangan karbon pohon, 402,25 ton per ha $(96 \%)$, dan tumbuhan bawah 16,69 ton per ha (4\%). Berdasarkan penggunaan lahan, cadangan karbon terbesar berasal dari penggunaan lahan hutan lahan kering primer sebesar 187,59 ton per ha, hutan lahan kering sekunder 100,48 ton per ha, semak belukar 32,59 ton per ha $(7,78 \%)$, pertanian lahan kering 31,41 ton per ha $(7,5 \%)$, pertanian lahan kering campuran 59,25 ton per ha $(14,14 \%)$, savana 6,78 ton per ha $(1,62 \%)$ dan permukiman 0,84 ton per ha $(0,2 \%)$. Potensi serapan karbon dioksida oleh vegetasi pada hutan lindung Gunung Sirimau sebesar 1.537,50 ton $\mathrm{CO}_{2}$ per ha. Penyerapan terbesar berasal dari vegetasi tingkat pohon sebesar 1.476,25 ton $\mathrm{CO}_{2}$ per ha atau $96 \%$ dari total penyerapan $\mathrm{CO}_{2}$. Berdasarkan penggunaan lahannya, hutan lahan kering primer memiliki kemampuan penyerapan $\mathrm{CO}_{2}$ terbesar yaitu 688,45 ton $\mathrm{CO}_{2}$ per ha atau $44,78 \%$ dari total serapan $\mathrm{CO}_{2}$.
\end{abstract}

Kata kunci: cadangan karbon pohon dan tumbuhan bawah, serapan karbon, hutan lindung Sirimau, Pulau Ambon 


\section{PENDAHULUAN}

Hutan merupakan sumber daya alam yang sangat penting bagi kehidupan manusia dan makluk hidup lainnya, baik secara langsung, seperti hasil kayu dan keanekaragaman flora fauna, maupun tidak langsung seperti jasa lingkungan, pengatur tata air, dan sebagai penyimpan karbon. Greenpeace (2013) mengatakan bahwa hutan tropis disamping menyimpan banyak karbon dan keanekaragaman hayati yang penting, juga sangat penting bagi mata pencaharian dari ribuan komunitas lokal sekitar hutan. Konversi hutan secara besar-besaran ntuk lahan pertanian atau perkebunan telahmenjadikan Indonesia salah satu penghasil emisi gas rumah kaca terbesar.

Sebagai suatu ekosistem, hutan sangat berperan dalam siklus karbon (Apps et al., 2005; Hairiah, 2007; Liang et al., 2019). Siklus karbon dipengaruhi oleh beberapa kondisi antara lainjenis dan umur tegakan, lingkungan tempat tumbuh, aktifitas manusia dan perubahan iklim (Higgins et al., 2012). Hal ini menunjukkan bahwa kemampuan hutan dalam menyerap dan menyimpan karbon tidak sama, sehingga ketersediaan informasi mengenai cadangan karbon dari berbagai tipe hutan, jenis pohon, dan lingkungan tumbuhnya sangat penting (Masripatin et al., 2010, Manuri et al., 2012).Sebagai contoh, hasil penelitian Noor'an, dalam Masripatin et al. (2010) menunjukkan bahwa cadangan karbon diatas permukaan tanah pada hutan lindung sebesar 211,86 ton $\mathrm{C}$ per ha, dan hutan sekunder bekas tebangan berkisar 171,8-249,1 ton C per ha (Dharmawan dalam Masripatin et al., 2010), hasil ini lebih besar bila dibandingkan dengan cadangan karbon di hutan tanaman yang umumnya kurang dari 100 ton C per ha. Selanjutnya, Indrajaya (2013) melaporkan bahwa total karbon tersimpan dalam biomasa hutan lindung Long Ketrok adalah 304 ton per ha dengan jumlah karbon di atas permukaan tanah sebesar 255 ton per ha, sedangkan karbon tersimpan diatas permukaan tanah pada Arboretum Unila pada tahun 2016 sebesar
226,75 ton per ha (Banjarnahor et al., 2018). Sebaliknya, pada hutan rakyat yang tergolong hutan belum baik mempunyai cadangan karbon rata-rata 72,73 ton per ha, hasil ini tidak terlalu berbeda dengan kandungan karbon tersimpan pada hutan dengan kerapatan rendah dan kerapatan sedang, yaitu masingmasing 54,57 ton per ha dan 79,78 ton per ha (Ivando et al., 2019). Perbedaan ini disebabkan karena kegiatan yang bersifat merusak hutan mengakibatkan terjadinya perubahan dan komposisi jenis sehingga fungsi hutan sebagai penyerap karbon di atmosfer juga terus menurun (Pandey et al., 2019).

Kota Ambon memiliki kawasan hutan seluas 9.511 ha, termasuk didalamnya hutan lindung Sirimau seluas $3.449 \mathrm{Ha}$, yang merupakan kawasan resapan air dari beberapa sumber air baku di kota Ambon. Disisi lain, pertumbuhan penduduk yang cepat di kota Ambon telah mendorong alih fungsi lahan berjalan cepat hingga masuk dalam hutan lindung. Oleh sebab itu, dalam Hutan lindung Gunung Sirimau dapat ditemukan berbagai penggunaan lahan, termasuk pemukiman. Laporan Dinas Kehutanan Provinsi Maluku, hingga tahun 2018 telah terjadi perubahan penggunaan lahan di dalam hutan lindung Gunung Sirimau seluas 41 ha, masing-masing 14 ha pada areal hutan (primer dan sekunder) dan 27 ha pada areal non-hutan seperti pertanian lahan kering, pertanian lahan kering dan campuran. Disamping itu, kebakaran hutan tahun 2014, 2016, 2018 dan 2019 berturut-turut telah merubah baik komposisi tegakan maupun tumbuhan bawah pada hutan lindung.

Penelitian ini bertujuan mengkaji simpanan karbon atas permukaan tanah di hutan lindung Sirimau setelah terjadi perubahan penggunaan baik di areal hutan maupun di areal non-hutan sejak tahun 2010.

\section{BAHAN DAN METODE}

Penelitian ini dilaksanakan di hutan lindung Sirimau Kota Ambon, seluas 3.449 ha.

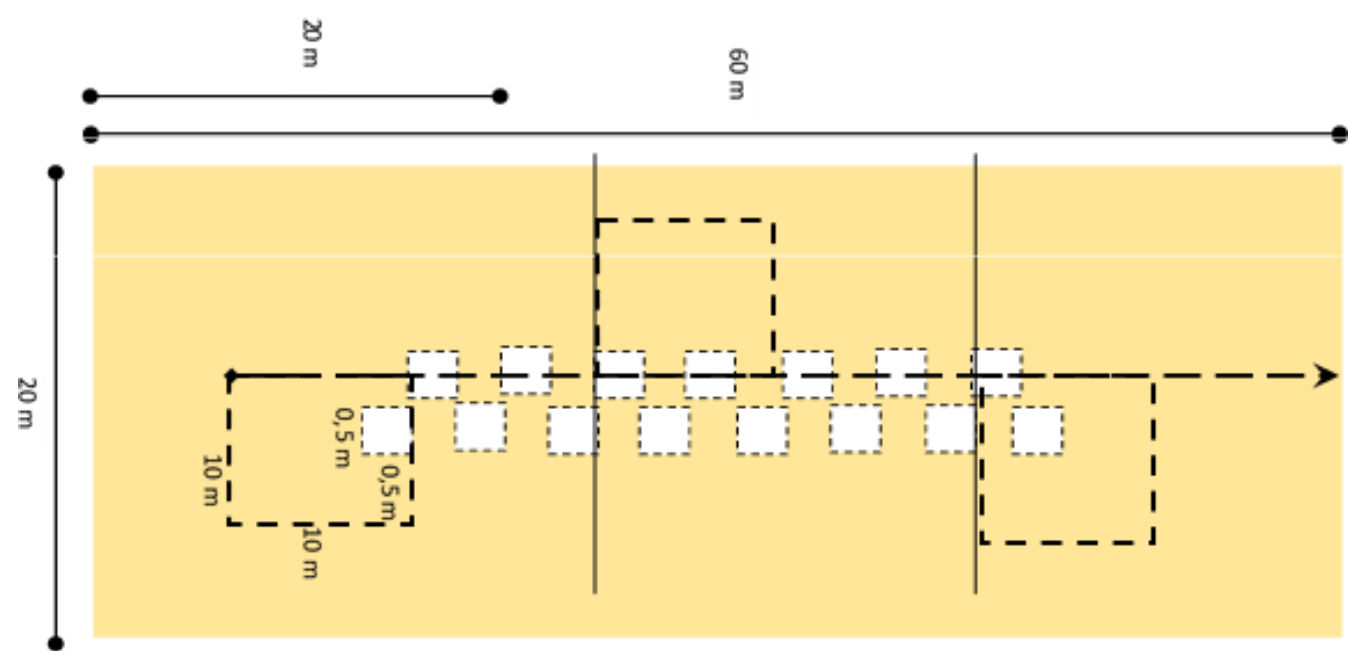

Gambar. 1. Contoh petak sampling di lokasi peneelitian 
Pembuatan peta penggunaan lahan dilakukan berdasarkan peta penutupan lahan tahun 2018 (BPKH Wilayah IX Ambon, 2018), dan dikelompokkan (menggunakanArc-GIS) menjadi pengunaan 7 penggunaan lahan, yaitu hutan lahan kering primer (HLKP), hutan lahan kering sekunder (HLKS), semak belukar (SB), pertanian lahan kering (PLK), pertanian lahan kering campuran (PLKC), padang rumput/savanna $(\mathrm{PR} / \mathrm{S})$, dan pemukiman $(\mathrm{P})$. Pengambilan sampel dilakukan pada semua penggunaan lahan dengan mempertimbangkan luas dan keragaman vegetasi pada masing-masing penggunaan lahan.

Teknik pengambilan sampel diadaptasi dari metode Hairiah et al. (2001, 2011) dan Wibowo et al. (2013), yaitu non-destructive untuk pohon dan destructive untuk tumbuhan bawah. Ukuran petak sampel utama dalam penelitian ini adalah $20 \mathrm{~m} \times 60 \mathrm{~m}$ yang dibagi menjadi 3 petak ukuran $20 \mathrm{~m} \times 20 \mathrm{~m}$, dan pada ketiga petak ini terdapat petak sedang $10 \mathrm{~m} \times 10 \mathrm{~m}$, dan petak kecil $0,5 \mathrm{~m} \times 0,5 \mathrm{~m}$. Petak utama dan sedang digunakan untuk sampling pohon $(d b h 1.3 \mathrm{~m})$ masingmasing dengan diameter $\geq 30 \mathrm{~cm}$ dan $5-30 \mathrm{~cm}$, sedangkan petak kecil untuk sampling tumbuhan bawah $(d b h<5 \mathrm{~cm})$. Contoh petak sampling disajikan pada Gambar 1.

Analisis data terdiri dari perhitungan biomasa dan cadangan karbon (pohon dan tumbuhan bawah) pada semua penggunaan lahan dengan mengacu pada Hairiah et al. $(2001 ; 2011)$.

\section{HASIL DAN PEMBAHASAN}

\section{Vegetasi Penyusun Hutan Lindung Sirimau}

Hasil penelitian menunjukkan bahwa penggunaan lahan di hutan lindung Sirimau terdiri dari hutan (hutan lahan kering primer dan hutan lahan kering sekunder) dan penggunaan lahan bukan hutan (semak belukar, pertanian lahan kering, pertanian lahan kering campuran, padang rumput/savanah, dan permukiman). Vegetasi penyusun hutan lindung Sirimau, yaitu:

1. Tegakan hutan yang didominasi oleh akasia (Acacia mangium), salawaku (Paraserienthes falcataria), kenari (Canarium commune), jambu hutan (Eugenia sp.), melinjo/ganemo (Gentum gnemon), gayang (Inocarpus edulis), pule (Alstia solaris), lenggua (Pterocarpus indicus), palala (Knema sp.), gondal (Ficus septica), husor (Garcinia cornea), kayu titi (Gmelina molucana), nani (Metrosideros petiolata), kenanga (Cananga odoratum), samama (Anthocephalus macrophyllus), Timun sp., papeda uba (Gaertnera sp), sapar (Alphitia zizypoides), nanari (Canarium sylvestre), Arupa (Ganua boerlageana), waru (Hibiscus tiliceus), gaharu (Aquilaria malacensis), kayu merah (Eugenia rumphii).

2. Tegakan bukan hutan (tanaman perkebunan dan buah-buahan), seperti cengkih (Syzygium aromaticum), pala (Myristica fragrans), kelapa (Cocos nucifera), jenis buah-buahan (MPTS) durian (Durio zibethinus), langsat (Lansium domesticum), mangga (Mangifera indica), kecapi (Sandoricum koetjape), bicang (Mangifera foetida), campada (Arthocarpus integer), Mangustan (Garcinia mangostana), dan sambutan (Naphelium lappaceum) dan lain-lain.

3. Vegetasi penyusun tumbuhan bawah didominasi jenis-jenis: (1) paku-pakuan (Pterydophyta), seperti paku kawat (Lycopodium clavatum), paku ekor (Dryopteris filxmas), suplir (Adiantum cuneatum), semanggi (Marsilea crenata), dan paku sarang burung (Asplenium sp.), (2) jenis rumput-rumputan, seperti alang-Alang (Imperata cylindrica), rumput teki (Cyperus rotundus), rumput resam (Dicranopteris linearis), sunggah-sunggah (Ageratum sp.), kapinawang (Colocasia esculenta) dan rutu-rutu (Selaginella plana), (3) putri malu (Mimosa pudica), dan (4) sirih (Piper crocatum).

\section{Kandungan Biomasa dan Cadangan Karbon Pohon}

Kandungan biomasa pohon merupakan penjumlahan dari kandungan biomassa tiap organ pohon yang merupakan gambaran total material organik hasil dari fotosintesis (Hairiah dan Rahayu, dalam Tuah et al., 2017). Hasil perhitungan biomasa dan cadangan pohon hutan lindung Sirimau disajikan Tabel 1 dan Gambar 2.

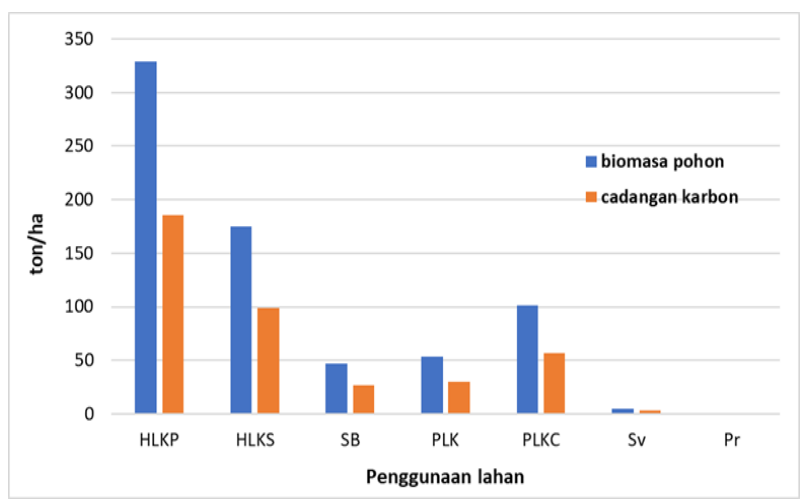

Gambar 2. Total biomasa dan karbon pohon pada hutan lindung Sirimau

Tabel 1 dan Gambar 2 menunjukkan bahwa total biomasa pohon di hutan lindung Sirimau adalah 71,32 $\mathrm{kg}$ per $\mathrm{m}^{2}$ dengan sebaran yang berbeda-beda pada setiap penggunaan lahan. Biomasa pohon terbesar ditemukan pada penggunaan lahan HLKP sebesar 32,99 $\mathrm{kg}$ per $\mathrm{m}^{2}$ atau $46,26 \%$ dan terkecil pada penggunaan lahan savana dan pemukiman yaitu masing-masing 0,54 $\mathrm{kg}$ per $\mathrm{m}^{2}(0,76 \%)$ dan $0,04 \mathrm{~kg}$ per $\mathrm{m}^{2}(0,06 \%)$. Perbedaan ini dapat dikaitkan dengan keragaman jumlah dan jenis tegakan yang menyebabkan diameter batang sampel yang ditemukan pada setiap penggunaan lahan berbeda-beda (HLKP > $40 \mathrm{~cm}$, HLKS $(20-80 \mathrm{~cm}$ ). Pengaruh positif diameter batang terhadap kandungan biomasa pohon telah dilaporkan Tuah et al. (2017) dan Marulan et al. (2015). 
Tabel 1. Total biomassa dan cadangan karbon pohon pada hutan lindung Sirimau

\begin{tabular}{rlrrr}
\hline \multirow{2}{*}{ No } & \multicolumn{1}{c}{ Penggunaan Lahan } & $\begin{array}{c}\text { Biomasa Pohon } \\
\text { (ton per ha) }\end{array}$ & $\begin{array}{c}\text { Cadangan Karbon } \\
\text { (kg per pohon) }\end{array}$ & $\begin{array}{c}\text { Cadangan Karbon } \\
\text { (ton per ha) }\end{array}$ \\
\hline 1 & Hutan Lahan Kering Primer & 329,9 & $18.570,52$ & 185,71 \\
2 & Hutan Lahan Kering Sekunder & 175,3 & $9.889,23$ & 98,89 \\
3 & Semak Belukar & 47,4 & $2.670,66$ & 26,71 \\
4 & Pertanian Lahan Kering & 53,4 & $3.012,12$ & 30,12 \\
5 & Pertanian Lahan Kering Campuran & 101,3 & $5.715,46$ & 57,15 \\
6 & Savana & 5,4 & 305,57 & 3,06 \\
7 & Pemukiman & 0,4 & 24,88 & 0,25 \\
\hline \multicolumn{2}{r}{ Jumlah } & 713,20 & $40.188,44$ & 401,89 \\
\hline
\end{tabular}

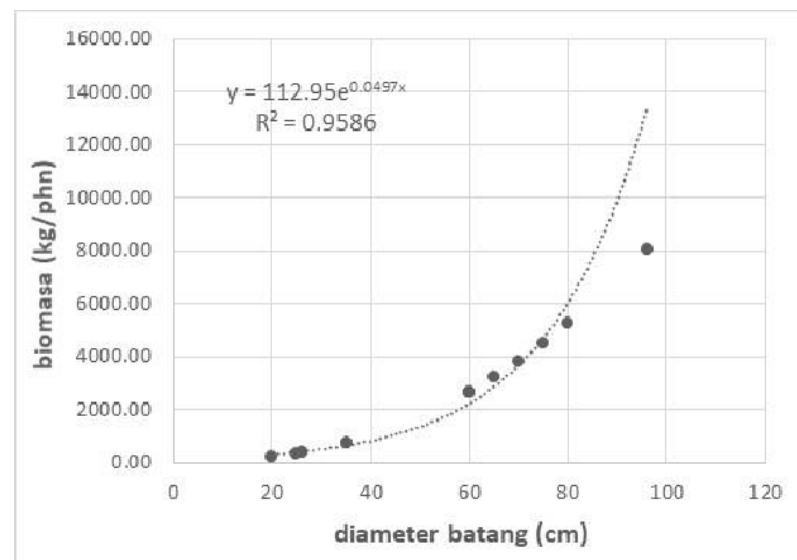

(a)

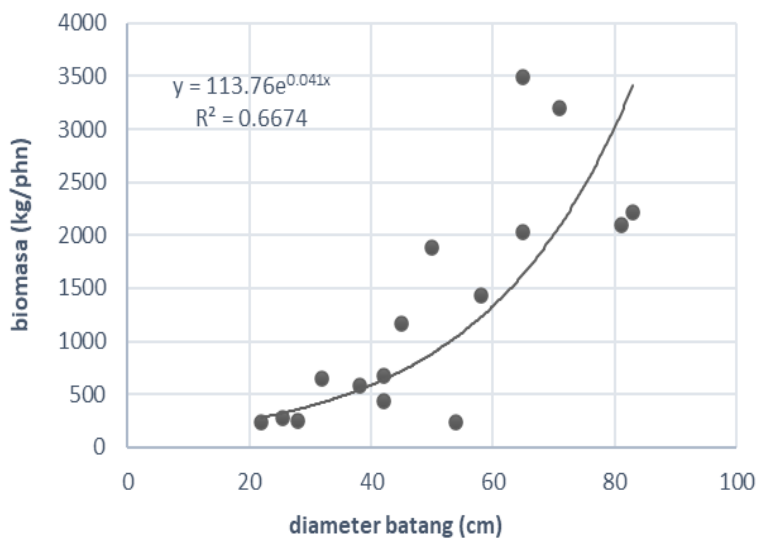

(b)

Gambar 3. Contoh pengaruh diameter batang terhadap biomasa pohondi hutan lindung Sirimau (a) hutan lahan kering primer (HLKP - Soya), (b) hutan lahan kering sekunder (HLKS - Rutg)

Hasil penelitian ini menunjukkan bahwa cadangan karbon pohon di hutan lindung Sirimau berbeda pada setiap penggunaan lahan dan besarnya cadangan karbon pohon bervariasi menurut jumlah biomasa pohonnya, yaitu semakin tinggi biomasa pohon semakin tinggi cadangan karbonnya, dan sebaliknya. Total cadangan karbon di hutan lindung Sirimau sebesar 401,89 ton per ha, dan cadangan karbon tertinggi ditemukan pada penggunaan lahan hutan lahan kering primer yaitu sebesar 185,71 ton per ha, diikuti hutan lahan kering sekunder dan pertanian lahan kering campuran, masing-masing sebesar 98,89 ton per ha dan 57,15 ton per ha. Sedangkan cadangan karbon terendah ditemukan pada penggunaan lahan savana dan pemukiman, yaitu 3.06 ton per ha dan 0.25 ton per ha. Biomasa dan cadangan karbon pohon yang bervariasi padasetiap penggunaan lahan di hutan lindung Sirimau disebabkan karena adanya perbedaan pada jumlah dan jenis vegetasi pohon dan pada pertumbuhan tegakan pohon, sehingga diameter batang yang ditemukan pada hutan lindung Sirimau berbeda-beda pada setiap penggunaan lahan.Pada penggunaan lahan HLKP, tegakan hutan bercampur dengan tanaman buah-buahan umur panjang dengan kerapatan tutupan yang tinggi sehingga menyebabkan tingginya biomasa pohon yaitu, 329,9 ton per ha dan cadangan karbon 185,71 ton per ha. Selain kerapatan tegakan, tingginya biomasa pohon pada penggunaan lahan ini dapat dikaitkan dengan keragaman jenis vegetasi hutan yang masih tinggi (sekitar 60\% dari total sampling) dan masih dijumpai tegakan yang mempunyai diameter batang $>50 \mathrm{~cm}$, seperti Canarium sylvestre, Eugenia sp., Garcinia cornea, dan Metrosideros petiolate. Sebaliknya, pada penggunaan lahan HLKS biomasa pohon menurun menjadi 175,3 ton per ha sehingga cadangan karbon pohon menjadi 98.89 ton per ha. Penurunan ini terjadi karena jumlah dan jenis vegetasi hutan dan jumlah pohon yang berdiameter $>50 \mathrm{~cm}$ lebih sedikit dibandingkan dengan penggunaan lahan hutan lahan kering primer. Pengaruh diameter terhadap biomasa pohon pada HLKP dan HLKS disajikan pada Gambar 3. Jika dibandingkan dengan penelitian sebelumnya (Patampang et al., 2011), cadangan karbon pada hutan lindung Sirimau pada tahun 2019 telah mengalami penurunan $49,79 \%$ pada penggunaan lahanhutan lahan kering primer, 59,13\% pada hutan lahan kering sekunder, $79,39 \%$ pada pertanian lahan keringsebesar $79,39 \%$ dan $73,06 \%$ pada penggunaan lahan semak belukar, sedangkan pada penggunaan lahan pertanian lahan kering campuran ada penambahan sebesar 57,15 ton per ha. Hasil ini menunjukkan bahwatutupan lahan pada hutan lindung Sirimau telah 
mengalami degradasi rata-rata sebesar $51 \%$, sehingga menyebabkan penurunan biomasa dan cadangan karbon yang cukup besar, yaitu 499.54 ton per ha $(59,38 \%)$ selama 9 tahun atau sekitaar 55,5 ton per ha setiap tahun (Gambar 4).

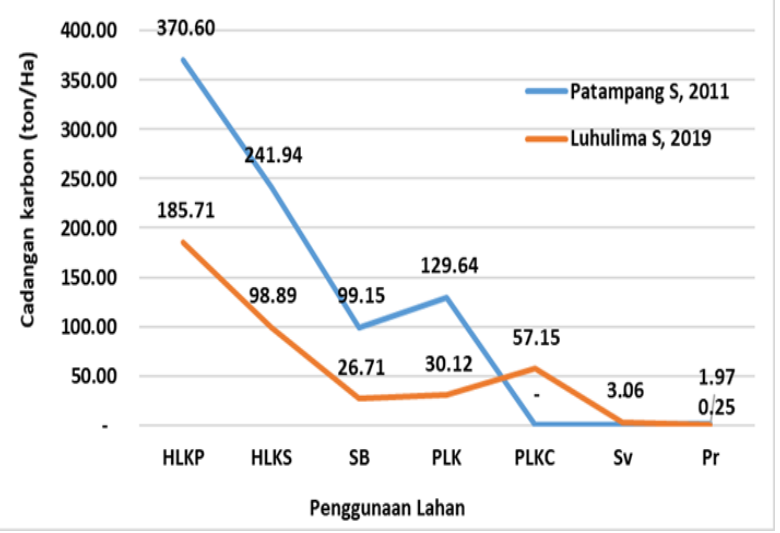

Gambar 4. Perbandingan cadangan karbon pohon di hutan lindung Sirimau tahun 2011 dan 2019

\section{Biomasa dan Cadangan Karbon Tumbuhan Bawah}

Karbon tersimpan tidak hanya terdapat pada tegakan saja, tetapi juga tersimpan pada tumbuhan bawah, walaupun pada ekosistem non hutan (SB, PLK, PLKC, PR/S, dan P) ditemukan lebih banyak jenis tumbuhan bawah daripada ekosistem hutan.Pada hutan lindung Sirimau, ekosistem hutan (HLKP dan HLKS) didominasi oleh tumbuhan bawah sepertirumput resam (Dicranopteris linearis) dan paku ekor (Dryopteris filxmas), sedangkan pada ekosistem non hutan lebihbervariasi (berbagai jenis paku-pakuan dan rumput-rumputan, putri malu dan sirih).

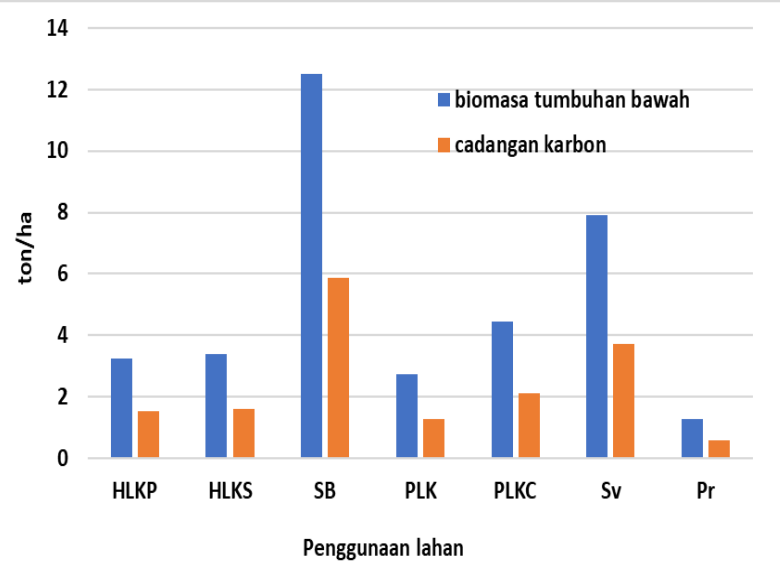

Gambar 5. Total biomasa dan cadangan karbon tumbuhan bawah pada hutan lindung Sirimau

Tabel 2 dan Gambar 5 menunjukkan bahwa total biomasa dan cadangan karbon tumbuhan bawah di hutan lindung Sirimau masing-masing sebesar 35,51 ton per ha dan 16,69 ton per ha. Biomasa dan cadangan karbon tumbuhan bawah terbesar berasal dari pengunaan lahan SB, yaitu 12,51 ton per ha dan 5,88 ton per ha, diikuti PR/S7,92 ton per ha dan 3,72 ton per ha, dan PLKC sebesar 4,46 ton per ha dan 2,10 ton per ha, sedangkan cadangan karbon terendah ditemukan pada penggunaan lahan lahan pemukiman sebesar 0,59 ton per ha. Tingginya biomasa dan cadangan karbon pada penutupan lahan SB disebabkan oleh rapatnya tumbuhan bawah yang terdiri dari jenis paku-pakuan (Pterydophyta), seperti paku kawat (Lycopodium clavatum), paku ekor (Dryopteris filxmas), suplir (Adiantum cuneatum), semanggi (Marsilea crenata). Menurut Azham (2015), tingginya cadangan karbon tumbuhan bawah pada penggunaan lahan SB dan PR/S karena pada kedua penggunaan lahan ini tidak terdapat vegetasi berkayu yang relatif besar dengan tutupan tajuk yang rapat sehingga sinar matahari dapat menembus langsung ke lantai hutan dan menstimulir pertumbuhan biji-biji jenis-jenis pioner dengan cepat, seperti alangalang (Imperata), Mallotus sp., Humalantus sp., dan Melastoma sp. Sebaliknya, pada penggunaan lahan PLK dan PLKCmasih dijumpai vegetasi pohon dengan tutupan tajuk yang masih baik sehingga mencegah cahaya matahari mencapai lantai hutan. Hal ini menyebabkan pertumbuhan vegetasi bawah menjadi tertekan dan tidak dapat tumbuh dengan baik, sehingga kandungan biomassa tumbuhan bawah pada penggunaan lahan HLKP, HLKS, PLK, dan PLKC menurun dan mempengaruhi besarnya cadangan karbonnya lebih kecil dari penggunaan lahan semak belukar dan savana (Hanafi dan Bernardianto, 2012).

Tabel 2. Total biomasa dan cadangan karbon tumbuhan bawah pada hutan lindung Sirimau

\begin{tabular}{|c|c|c|c|c|}
\hline No & $\begin{array}{l}\text { Penggunaan } \\
\text { Lahan }\end{array}$ & $\begin{array}{l}\text { Biomasa } \\
\text { ton per ha }\end{array}$ & $\begin{array}{c}\text { Cadangan C } \\
\text { ton per ha }\end{array}$ & $\begin{array}{c}\text { Persentase } \\
(\%)\end{array}$ \\
\hline 1 & $\begin{array}{l}\text { Hutan Lahan } \\
\text { Kering Primer }\end{array}$ & 3,23 & 1,52 & 9,10 \\
\hline 2 & $\begin{array}{l}\text { Hutan Lahan } \\
\text { Kering } \\
\text { Sekunder }\end{array}$ & 3,38 & 1,59 & 9,52 \\
\hline 3 & $\begin{array}{l}\text { Semak } \\
\text { Belukar }\end{array}$ & 12,51 & 5,88 & 35,24 \\
\hline 4 & $\begin{array}{l}\text { Pertanian } \\
\text { Lahan Kering }\end{array}$ & 2,74 & 1,29 & 7,72 \\
\hline 5 & $\begin{array}{l}\text { Pertanian } \\
\text { Lahan Kering } \\
\text { Campuran }\end{array}$ & 4,46 & 2,10 & 12,57 \\
\hline 6 & $\begin{array}{l}\text { Padang } \\
\text { rumput } \\
\text { /Savana }\end{array}$ & 7,92 & 3,72 & 22,31 \\
\hline \multirow[t]{2}{*}{7} & Pemukiman & 1,26 & 0,59 & 3,53 \\
\hline & Jumlah & 35,51 & 16,69 & 100,00 \\
\hline
\end{tabular}

Jika hasil penelitian ini dibandingkan dengan penelitian sebelumnya (Patampang et al., 2011) 
(Gambar 6), dapat dilihat bahwa dalam kurun waktu 10 tahun (2010-2019) telah terjadi peningkatan total cadangan karbon tumbuhan bawah di hutan lindung Sirimau sebesar 11,04 ton per ha $(66,15 \%)$ atau 0,92 ton per ha/thn $(5,51 \%$ per tahun). Peningkatan cadangan karbon terbesar terjadi pada pengunaan lahan semak belukar yaitu 5.88 ton per ha, diikuti savana 3,72 ton per ha, pertanian lahan kering campuran 2,10 ton per ha, hutan lahan kering sekunder 1,59 ton per ha, hutan lahan kering primer 1,52 ton per ha dan pertanian lahan kering 1,29 ton per ha. Sedangkan cadangan karbon tumbuhan bawah terendah berasal dari penutupan lahan pemukiman sebesar 0,59 ton per ha.

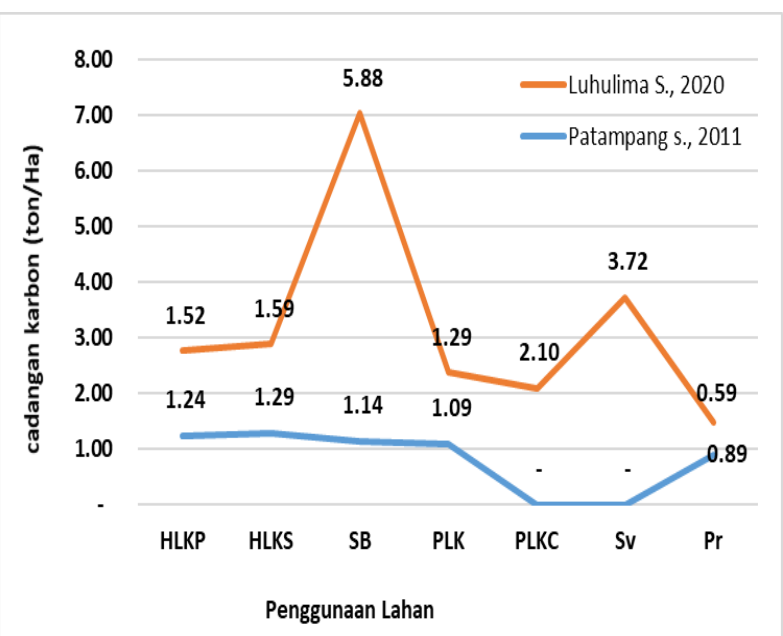

Gambar 6. Perbandingan cadangan karbon tumbuhan bawah pada hutan lindung Sirimau tahun 2011 dan tahun 2019

Perubahan cadangan karbon tumbuhan bawah di hutan lindung Sirimau disebabkan karena adanya perubahan tutupan lahan akibat kebakaran yang terjadi pada tahun 2014, 2016, 2018 dan 2019. Kebakaran yang terjadi dalam 4 tahun ini menyebabkan hutan lindung kehilangan pohon dan pengurangan tutupan atas dan memberikan ruang tumbuh bagi tumbuhan bawah untuk berkembang dengan cepat, karena hilangnya tutupan atas sebagai penaung memberikan sinar matahari yang lebih banyak bagi tumbuhan bawah untuk berfotosintesis dan menghasilkan karbon organik dalam bentuk biomassa yang lebih banyak. Siahaan et al. (2020) mengatakan cadangan karbon tumbuhan bawah cenderung meningkat karena setelah 1,5 tahun kebakaran tumbuhan bawah bertumbuh dengan cepat.

Kandungan biomasa tumbuhan bawah ditemukan tinggi pada penggunaan lahan semak belukar dan savanna, yaitu masing-masing sebesar $1,25 \mathrm{~kg}$ per $\mathrm{m}^{2}$ dan $0,79 \mathrm{~kg}$ per $\mathrm{m}^{2}$, sedangkan biomasa terendah ditemukan pada pertanian lahan kering dan pemukiman, yaitu $0,27 \mathrm{~kg}$ per $\mathrm{m} 2$ dan $0,13 \mathrm{~kg}$ per $\mathrm{m} 2$. Hasil ini mengindikasikan bahwa biomasa tumbuhan bawah yang tersebar pada penggunaan lahan yang kurang tutupan atas atau yang secara langsung dibawah pengaruh matahari mempunyai biomasa lebih besar dibandingkan dengan penggunaan lahan yang mempunyai tutupan atas lebih rapat dan kurang mendapat cahaya matahari secara langsung. Purwanto et al. (2012) mengatakan bahwa pada penggunaan lahan semak belukar yang mempunyai kerapatan tajuk rendah memungkinkan sinar matahari masuk ke lantai hutan lebih banyak sehingga menstimulir biji-biji jenis pionir untuk tumbuh lebih banyak dibandingkan pada hutan sekunder yang mempunyai penutupan tajuk lebih rapat, sehingga cahaya tidak cukup untuk proses fotosintesis. Disamping itu, banyaknya sinar matahari juga menyebabkan proses dekomposisi berlangsung lebih cepat sehingga meningkatkan kesuburan tanah. Oleh sebab itu, selain kondisi kanopi di atas tumbuhan bawah, biomasa tumbuhan bawah pada suatu kawasan juga dipengaruhi oleh kesuburan tanahnya (Lestari et al., 2019; Heriyanto et al., 2020).

\section{Total Cadangan Karbon pada Hutan LIndung Sirimau}

Tabel 3 menunjukkan bahwa total cadangan karbon (pohon dan tumbuhan bawah) di hutan lindung Sirimau adalah sebesar 418,57 ton per ha, yang terdiri dari cadangan pohon, yaitu 402,25 ton per ha dan tumbuhan bawah 16,69 ton per ha. Pada cadangan karbon pohon, kontribusi karbon terbesar berasal dari penggunaan lahan hutan lahan kering primer yaitu 187,22 ton per ha dan hutan lahana kering sekunder sebesar 100,48 ton per ha, karena kedua penggunaan lahan ini mempunyai jenis dan jumlah vegetasi hutan yang masih cukup tinggi, dan beberapa tegakan pohon mempunyai diameter batang $>50 \mathrm{~cm}$. Total cadangan karbon menurun seiring berkurangnya tegakan pohon pada setiap penggunaan lahan. Oleh sebab itu total cadangan karbon terendah dijumpai pada penggunaan lahan savanna dan pemukiman yang hanya mempunyai beberapa pohon seperi Ficus Elastica, Eugenia sp., dan Cocos nucifera. Berdasarkan hasil penelitian ini, hutan lindung Sirimau dengan luas 3.449 ha mampu menyimpan karbon sebesar 218.772 t. Cadangan karbon terbesar ditemukan pada hutan lahan kering sekunder, yaitu 75.586 ton atau $34,55 \%$ dari total cadangan karbon, diikuti dengan hutan lahan kering primer sebesar 56.190 ton $(25,68 \%$ ), semak belukar 43.003 ton $(19,66 \%)$, pertanian lahan kering campuran 41.358 ton $(18,90 \%)$, sedangkan total cadangan karbon terkecil ditemukan pada penggunaan lahan pemukiman, yaitu 190 ton $(0,09 \%)$.

\section{Potensi Serapan Karbon $\left(\mathrm{CO}_{2}\right)$}

Hutan berfungsi sebagai penyerap karbon dan pengemisi karbon melalui tanaman atau pohon yang ada di dalamhutan (Manuri et al., 2012). Menurut Murdiyarso et al. (2005) proses penyimpanan karbon di dalam tanaman yang sedang tumbuh disebut sebagai sekuestrasi karbon (carbon sequestration), dan jumlah karbon yang ditimbun dalam tanaman sangat bergantung pada jenis dan sifat tanaman itu sendiri. 
Tabel 3. Total simpanan karbon di atas permukaan pada hutan lindung Sirimau

\begin{tabular}{|c|c|c|c|c|c|c|c|}
\hline \multirow[b]{2}{*}{ No } & \multirow[b]{2}{*}{ Penggunaan Lahan } & \multirow[b]{2}{*}{ Luas (ha) } & \multicolumn{2}{|c|}{ Stok karbon (ton per ha) } & \multirow[b]{2}{*}{$\begin{array}{l}\text { Total stok karbon } \\
\text { (ton per ha) }\end{array}$} & \multirow{2}{*}{$\begin{array}{c}\text { Total } \\
\text { simpanan } \\
\text { karbon } \\
\text { (ton) } \\
\end{array}$} & \multirow[b]{2}{*}{$\begin{array}{c}\text { Persentase } \\
(\%)\end{array}$} \\
\hline & & & Pohon & $\begin{array}{l}\text { Tumbuhan } \\
\text { Bawah }\end{array}$ & & & \\
\hline 1 & Hutan Lahan Kering Primer & 300.12 & 186,07 & 1,52 & 187.22 & 56.190 & 25.68 \\
\hline 2 & $\begin{array}{l}\text { Hutan Lahan Kering } \\
\text { Sekunder }\end{array}$ & 752.24 & 98,89 & 1,59 & 100.48 & 75.586 & 34.55 \\
\hline 3 & Semak Belukar & 1319.60 & 26,71 & 5,88 & 32.59 & 43.003 & 19.66 \\
\hline 4 & Pertanian Lahan Kering & 57.28 & 30,12 & 1,29 & 31.41 & 1.799 & 0.82 \\
\hline 5 & $\begin{array}{l}\text { Pertanian Lahan Kering } \\
\text { Camp. }\end{array}$ & 697.99 & 57,15 & 2,10 & 59.25 & 41.358 & 18.90 \\
\hline 6 & Padang rumput / Savana & 95.52 & 3,06 & 3,72 & 6.78 & 648 & 0.30 \\
\hline 7 & Pemukiman & 226.25 & 0,25 & 0,59 & 0.84 & 190 & 0.09 \\
\hline & Jumlah & 3.449 & 402,25 & 16,69 & 418,57 & 218.772 & 100.00 \\
\hline
\end{tabular}

Tabel 4. Potensi serapan karbon pada hutan lindung Sirimau

\begin{tabular}{|c|c|c|c|c|c|c|c|}
\hline \multirow{2}{*}{ No } & \multirow{2}{*}{ Penggunaan Lahan } & \multicolumn{2}{|c|}{$\begin{array}{l}\text { Stok karbon } \\
\text { (ton per ha) }\end{array}$} & \multicolumn{3}{|c|}{ Penyerapan $\mathrm{CO}_{2}$ (ton per ha) } & \multirow{2}{*}{$\begin{array}{l}\text { Persentase } \\
\quad(\%)\end{array}$} \\
\hline & & Pohon & $\begin{array}{c}\text { Tumbuhan } \\
\text { Bawah }\end{array}$ & Pohon & $\begin{array}{l}\text { Tumb. } \\
\text { Bawah }\end{array}$ & Jumlah & \\
\hline 1 & $\begin{array}{l}\text { Hutan Lahan Kering } \\
\text { Primer }\end{array}$ & 186,07 & 1,52 & 682,87 & 5,58 & 688,45 & 44,78 \\
\hline 2 & $\begin{array}{l}\text { Hutan Lahan Kering } \\
\text { Sekunder }\end{array}$ & 98,89 & 1,59 & 362,93 & 5,83 & 368,76 & 23,98 \\
\hline 3 & Semak Belukar & 26,71 & 5,88 & 98,01 & 21,58 & 119,60 & 7,78 \\
\hline 4 & Pertanian Lahan Kering & 30,12 & 1,29 & 110,54 & 4,73 & 115,28 & 7,50 \\
\hline 5 & $\begin{array}{l}\text { Pertanian Lahan Kering } \\
\text { Campuran }\end{array}$ & 57,15 & 2,10 & 209,76 & 7,70 & 217,46 & 14,14 \\
\hline 6 & Padang rumput / Savana & 3,06 & 3,72 & 11,21 & 13,67 & 24,88 & 1,62 \\
\hline \multirow[t]{2}{*}{7} & Pemukiman & 0,25 & 0,59 & 0,91 & 2,16 & 3,08 & 0,20 \\
\hline & Jumlah & 402,25 & 16,69 & $1.476,25$ & 61,25 & $1.537,50$ & 100,00 \\
\hline
\end{tabular}

Tabel 4 menunjukkan bahwa hutan lahan kering primer (HLKP) mempunyai kemampuan penyerapan karbon terbesar $(688,45$ ton per ha) melalui penyerapan oleh pohon (682,87 ton per ha), sedangkan terendah adalah padang rumput/savanna (24,88 ton per ha). Tingginya serapan karbon yang dihasilkan vegetasi pohon atau penggunaan lahan hutan lahan kering primer disebabkan oleh hutan/pohon memiliki kanopi atau tutupan tajuk yang besar sehingga dengan jumlah daun yang banyak mampu menyerap karbon yang banyak pula, sebaliknya tumbuhan bawah dan penggunaan lahan padang rumput/savana memiliki serapan karbon dioksida yang rendah karena tidak memiliki tajuk yang banyak atau luas permukaan daun kecil. Yuningsih et al. (2018) mengatakan bahwa hutan yang masih banyak tegakan pohon berdiameter $>30 \mathrm{~cm}$ memiliki kemampuan dalam menyerap karbon cukup tinggi.

\section{KESIMPULAN}

Kesimpulan-kesimpulan dari penelitian ini adalah sebagai berikut:

1. Total ketersediaan karbon pada hutan lindung Gunung Sirimau adalah 418,98 ton per ha, yang berasal dari cadangan karbon pohon, 402,25 ton per ha $(96 \%)$, dan tumbuhan bawah 16,69 ton per ha $(4 \%)$.

2. Berdasarkan penggunaan lahan, cadangan karbon terbesar berasal dari penggunaan lahan hutan lahan kering primer sebesar 187,59 ton per ha, hutan lahan kering sekunder 100,48 ton per ha, semak belukar 32,59 ton per ha $(7,78 \%)$, pertanian lahan kering 31,41 ton per ha $(7,5 \%)$, pertanian lahan kering campuran 59,25 ton per ha $(14,14 \%)$, padang rumput/savana 6,78 ton per ha $(1,62 \%)$ dan permukiman 0,84 ton per ha $(0,2 \%)$.

\section{DAFTAR PUSTAKA}

Apps, M.J., P. Bernier, and J.S. Bhatti. 2005. Forests in the global carbon cycle: Implications of climate change. In: J. Bhatti, R. Lal, M.J. Apps, M.A. Price (Eds.), p.175-200. Climate Change and Managed Ecosystems. Routledge, ISBN 9780367391485.

Higgins, P.A. and J. Harte. 2012. Carbon cycle uncertainty increases climate change risks and mitigation challenges. Journal of Climate 25: 7660-7668.

Banjarnahor, K.G., A. Setiawan, dan A. Darmawan. 2018. Estimasi perubahan karbon tersimpan di 
atas tanah di Arboretum Universitas Lampung. Jurnal Sylva Lestari 6(2): 51-59. DOI: http://dx.doi.org/10.23960/js12651-59.

Greenpeace. 2013. Identifying High Carbon Stock (HCS) Forest for Protection. Towards Defining Natural Forests and Degraded Lands in the Tropics Greenpeace Briefer on High Carbon Stock: March 2013, Greenpeace International, The Netherlands.

Hairiah, K. dan S. Rahayu S. 2007. Pengukuran Karbon Tersimpan di Berbagai Macam Penggunaan Lahan. World Agroforestry Centre ICRAF, SEA Regional Office, Bogor. University of Brawijaya, Malang, Indonesia.

Hairiah, K., S.M. Sitompul, M.van Noordwijk, and C. Palm. 2001. Methods for Sampling Carbon Stocks Above and Below Ground. International Centre for Research in Agroforestry Southeast Asian Regional Research Programme, Bogor, Indonesia.

Hairiah, K., S. Dewi, F. Agus, S. Velarde, A. Ekadinata, S. Rahayu, and M. van Noordwijk. 2011. Measuring Carbon Stocks Across Land Use Systems: A Manual. Bogor, Indonesia, $154 \mathrm{p}$ World Agroforestry Centre (ICRAF), SEA Regional Office, Bogor.

Hanafi, N. dan B. Bernardianto. 2010. Pendugaan Cadangan Karbon Pada Sistem Penggunaan Lahan di Areal PT. Sikatan Wana Raya. Laporan hasil penelitian. Kopertis Wilayah XI Kalimantan melalui Hibah. Lembaga Layanan Pendidikan Tinggi Wilayah XI Kalimantan.

Heriyanto, N.H., D. Priatna, dan I. Samsoedin. 2020. Struktur tegakan dan serapan karbon pada hutan sekunder kelompok hutan Muara Merang, Sumatera Selatan. Jurnal Sylva Lestari 8(2): 230-240. DOI: 10.23960/jsl28230-240.

Higgins, P.A, and J. Harte. 2012. Carbon cycle uncertainty increases climate change risks and mitigation challenges. Journal of Climate 25: 7660-7668.

Indrajaya, Y., 2013. Cadangan karbon hutan lindung Long Ketrok di Kabupaten Malinau, Kalimantan Timur untuk mendukung mekanisme Redd+. Jurnal Penelitian Sosial dan Ekonomi Kehutanan 10(2): 99-10. DOI: 10.20886/jpsek.2013.10.2.99-109.

Ivando, D., I.S. Banuwa, dan A. Bintoro, 2019. Karbon tersimpan pada berbagai tipe kerapatan tegakan di hutan rakyat Desa Sukoharjo I, Kecamatan Sukoharjo, Kabupaten Pringsewu. Jurnal Belantara 2(1): 53-61. DOI: 10.29303/jbl.v2i1.96.

Lestari, R.N., C. Wulandari, R. Safe'i, and A. Darmawan, 2019. Analysis of carbon above the ground as the indicator of forest health in protection forest registers 25. Journal of Sylva Indonesiana 2(1): 1-10. DOI: 10.32734/jsi. v2i1.873.
Liang, S., S. Peng, and Y. Chen. 2019. Carbon cycles of forest ecosystem in a typical climate transition zone under future climate change: a sase study of Shaanxi Province, China. Forest Journal 10(12): 1-17. DOI: 10.3390/f10121150.

Manuri, S., I. Kumara, W. Azwar, M. Irwan, Supriyanto, M. Firdaus, dan E. Somala. 2012. Inventarisasi Tegakan Hutan dan Cadangan Karbon di KPH Kapuas Hulu. Samarinda November 2021, Forests and Climate Programe German International Cooperation, Samarinda.

Masripatin N., K. Ginoga, G. Pari, W.S. Darmawan, K.A. Siregar, A. Wibowo, D. Puspasari, A.S. Utomo, N. Sakuntaladewi, M. Lugina, Indartik, W. Wulandari, S. Darmawan, I. Heryansah, N.M. Heriyanto, H.H. Seringoringo HH, R. Damayanti, D. Anggraeni, H. Krisnawati, R. Maryani, D. Apriyanto, dan B. Subekti. 2010. Cadangan Karbon pada Berbagai Tipe Hutan dan Jenis Tanaman di Indonesia. Pusat Penelitian dan Pengembangan Perubahan Iklim dan Kebijakan, Kampus Balitbang Kehutanan, Bogor.

Murdiyarso, D., H. Herawati, dan H. Iskandar. 2005. Carbon Sequestration and Sustainable Livelihoods. A Workshop Synthesis. Center for International Forestry Research, Bogor.

Pandey, S., R. Shukla, R. Saket, and D. Verma. 2019. Enhancing carbon stocks accumulation through forest protection and regeneration, a review. International Journal of Environment 8(1): 1621.

Patampang, S.B., A.I. Latupapua dan G. Mardiatmoko. 2011. Study on carbon stock estimation at the Sirimau Mountain protected forest to support Redd+ Program. In: A. S. Khouw, J.A.N. Masrikat, S. Tubalawon, P.A. Uneputty, J. Abrahamsz (Eds), p. 473-486. Proceeding of Intemational Seminar Ambon, 23 May 2011, Role Postgraduate Study in Sustainability Development of Archipelagic Communities.

Purwanto, R.H., Rohman, A. Maryudi, T. Yuwono, D.B. Permadi, dan M. Sanjaya. 2012. Potensi biomasa dan simpanan karbon jenis-Jenis tanaman berkayu di hutan rakyat Desa Nglanggeran, Gunungkidul, Daerah Istimewa Yogyakarta. Jurnal Ilmu Kehutanan 6(2): 128141. DOI: $10.22146 /$ jik.5778.

Siahaan, H., A. Kunarso, A. Sumadi, Purwanto, T. Rusolono, T. Tiryana, H. Sumantri, and B. Haasler. 2020. Carbon loss affected by fires on various forests and land types in South Sumatra. Indonesian Journal of Forestry Research 7(1): 15-25.

Tuah, N., R. Sulaeman, dan D. Yoza. 2017. Penghitungan biomassa dan karbon di atas permukaan tanah di hutan larangan adat Rumbio Kabupaten Kampar. Jurnal Online Mahasiswa Faperta Universitas Riau 4(1): 1-10.

Wibowo, A., I. Samsoedin, Nurtjahjawilasa, S.I. Zahrul, dan Muttaqin. 2013. Petunjuk Praktis 
Menghitung Cadangan Karbon Hutan. Pusat Penelitian dan Pengembangan Perubahan Iklim dan Kebijakan Badan Penelitian dan Pengembangan Kehutanan. Kementerian Kehutanan, Republik Indonesia, Jakarta.
Yuningsih, L., D. Lensari, dan N. Milantara. 2018. Perhitungan simpanan karbon atas permukaan di hutan lindung KPHP Meranti untuk mendukung program Redd. Jurnal Silva Tropika 2(3): 77-83. DOI: 10.32528/bioma.v5i2.4010. 